\title{
GIS BASED ANALYSIS OF SPATIAL DISTRIBUTION OF NDVI FOR AGRICULTURAL APPLICATIONS IN SALEM DISTRICT - TAMIL NADU
}

\author{
S. Venkadesh ${ }^{\mathrm{a},{ }^{*}}$, R. Jagannathan ${ }^{\mathrm{b}}$ and K.P. Ragunath ${ }^{\mathrm{c}}$ \\ a, ${ }^{*}$ Tamil Nadu Agricultural University, Coimbatore 641 003, Tamil Nadu, India - (venkadeshacrc@gmail.com) \\ ${ }^{\mathrm{b}}$ Retd. Professor, Tamil Nadu Agricultural University, Coimbatore 641 003, Tamil Nadu, India - jagan@tnau.ac.in \\ ${ }^{\mathrm{c}}$ Tamil Nadu Agricultural University, Coimbatore 641 003, Tamil Nadu, India - ragunathkp@tnau.ac.in
}

Commission III, WG III/10

KEY WORDS: NDVI, Biomass, MODIS, Crop growth, Agricultural Management

\begin{abstract}
:
Remote sensing satellites in recent years have emerged as a vital tool for generating the biophysical information, which further helps to evolve the optimal land use plan for sustainable development of an area. The natural resources are to be categorized to obtain the area best suitable for crop production so that they could be better utilized in agricultural planning. The Normalized Difference Vegetation Index (NDVI) has been widely used to monitor moisture-related vegetation condition. The 8-day composite and spatial resolution of $250 \mathrm{~m}$ for the years 2002-2012 have obtained from the Moderate Resolution Imaging Spectro-radiometer (MODIS) Surface Reflectance (MOD09A) used for grouping biomass. The MOD09A product was selected because it consisted of both visible and infrared bands, which is requisite for deriving NDVI. The NDVI was used to determine the biomass categorization had four classes B1 (NDVI of 0.06-0.10), B2 (0.1 to 0.2), B3 (0.2-0.4) and B4 ( $>0.4)$ which were rated as poor, moderate, good and excellent, respectively. Here, excellent biomass category was found to cover more area compared to other biomass categories. The per cent area covered under excellent category was $(88.7 \%)$ in Salem district. This showed that the agriculture area in this district is largely suitable for crop growth. The categorization of biomass as good to excellent in Salem might be due to the good seasonal (both monsoon) rainfall. It could pave way for better agricultural management and transfer of technology.
\end{abstract}

\section{INTRODUCTION}

For agriculture development and sustainable crop production, a country needs proper planning based on benchmark information. Since India has 328.729 million hectares of geographical area, the country needed strong evaluation of climate, soil and other natural resources including their potential. But this type of prescription has not been developed and exercised in the past. Agriculture is an essential component of societal well-being and agricultural production in turn influenced by health, water, ecosystems, biodiversity, economy, energy use and supply. Greater advances are being made to properly manage some of the variables involved in crop production, but success in management of climate is still limited.

In recent years, the advancement of satellite sensor technology has gradually improved the spatial resolution of polar orbiting satellite sensors that can cover large areas with high temporal frequency (such as MODIS and MERIS). These sensors can now observe the Earth with a spatial resolution of 250 to 300 meters with high temporal frequency (daily).

This spatial resolution is still too coarse to observe individual crop fields in many parts of Europe. However, it is likely that there will be at least some pixels where the fractional coverage of a single crop within the pixel is high. It is therefore necessary to obtain so-called "vegetation continuous fields" (Hansen et al. 2003) also called Area Fraction Images (AFI) that can be used to find those pixels and extract crop specific biophysical parameters from them with the advent of MODIS NDVI $250 \mathrm{~m}$ data, time series data analysis can be adapted for higher (moderate) resolution applications. However, the utility of the MODIS NDVI data products is limited by the availability of high-quality (e.g. cloud-free) data (Jin and Sader, 2005).
Remote Sensing (RS) and GIS are now providing new tools for advanced ecosystem management. The collection of remotely sensed data facilitates the synoptic analyses of Earth system function, patterning, and change at local, regional and global scales over time; such data also provide an important link between intensive, localized ecological research and regional, national and international conservation and management of biological diversity (Wilkie and Finn, 1996).

\section{STUDY AREA}

Salem is situated in Northwestern agro climatic zone of Tamilnadu and is bounded by Dharmapuri district on the north, Erode on the west, Villupuram and Cuddalore on the east and Namakkal and Perambalur on the south. The district occupies an area of 5,23,575 hectares, lying between $11.32^{\circ}$ and $11.98^{\circ} \mathrm{N}$ latitude and $77.64^{\circ}$ and $78.84^{\circ} \mathrm{E}$ longitude. The elevation in general ranges between 250 and 320 meters above mean sea level (MSL), while the hilly areas attain a height of about 1,200 to 1,500 meters above MSL. The mean annual rainfall is 875 $\mathrm{mm}$ and about 42 per cent of rainfall is received during the southwest monsoon season (June - September) and 39 per cent during northeast monsoon season (October-November). The location of the district for the study is presented in Fig 1.

\footnotetext{
* Corresponding author
} 


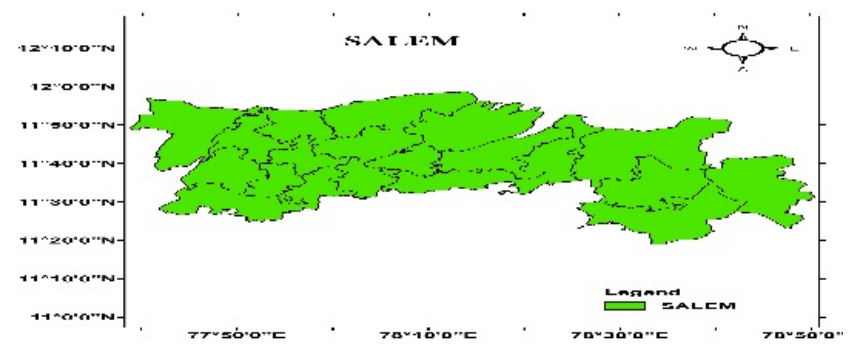

Figure 1. The study districts of Salem

\section{MATERIALS AND METHODS}

\subsection{Materials}

The MOD09A derived from MODIS Terra Daily Surface Reflectance was downloaded from the USGS server using the MODIS Reverb Tool (https://lpdaac.usgs.gov/get_data/reverb) for 10 years from January 1, 2002 to December 31, 2012. The product consisted of 46 images per year at the maximum available spatial resolution of $250 \mathrm{~m}$. The MOD09A product was selected because it consisted of both visible and infrared bands, which is the requisite for deriving NDVI. The whole study area is covered in 2 tiles of 8-day composite product (MOD09A). MODIS Reprojection tool was used to mosaic MODIS images, resampled them to other coordinate systems, and the images were exported in the same HDF format. The MODIS Reprojection Tool (v4.1) was used with the projection parameters and for sub-setting the coordinates for Salem districts.

\subsection{Methods}

The output format of MODIS Reprojection tool is the same as input, i.e. HDF format with the collection of visible and infrared bands. These bands were extracted from the ten year downloaded data with 46 composite per year and were used for the NDVI calculation. The math calculator module of ArcGIS 9.3 was used for this process. The following algorithm developed by Rouse et al. (1974) was used in this study:

$$
\text { NDVI }=\frac{(\text { R-NIR })}{(\text { R+NIR })}
$$

Where, R and NIR are the reflectance in the Red and Near-Infra Red spectral channels, respectively.

3.2.1 Creation of Biomass map: The derived NDVI was used to categorize biomass for the selected districts using methodology suggested by Bala et al. 2005. The Table 1 provides biomass category and their, respective NDVI values.

\begin{tabular}{|l|l|}
\hline Biomass category & \multicolumn{1}{|c|}{ NDVI values } \\
\hline B1 (Poor) & $0.06-0.10$ \\
\hline B2 (Moderate) & $0.10-0.20$ \\
\hline B3 (Good) & $0.20-0.40$ \\
\hline B4 (Excellent) & $>0.40$ \\
\hline
\end{tabular}

Table 1. Categories of Biomass as NDVI values
The Geographical Information System used in the study was ArcGIS 9.3 which was developed by ESRI Inc. This was used owing to its capability in reading and interpreting of data.

\section{RESULTS}

\subsection{Biomass categorization}

The Salem district area covered under each biomass category is presented in Table 2. the biomass of this district ascertained through NDVI values was found to be good to excellent.

\begin{tabular}{|l|l|l|l|l|l|}
\hline $\begin{array}{l}\text { Districts/Biomass } \\
\text { category }\end{array}$ & B1 & B2 & B3 & B4 & Total \\
\hline Salem & - & - & 35,825 & $2,81,375$ & $3,17,200$ \\
\hline
\end{tabular}

Tab 2. Salem district area (ha) covered under biomass category

The excellent biomass area covered was 88.7 per cent while the remaining 11.3 per cent fill under good biomass category.

\section{DISCUSSION}

Using NDVI ranges, the biomass was classified broadly into four categories viz., poor, moderate, good and excellent (Fig.2). For Salem district area under B4 category i.e., excellent is more followed by B3 (good) category. This showed that the agriculture area in this district are largely suitable for crop growth. The categorization of biomass as good to excellent in Salem might be due to the good seasonal (both monsoon) rainfall.

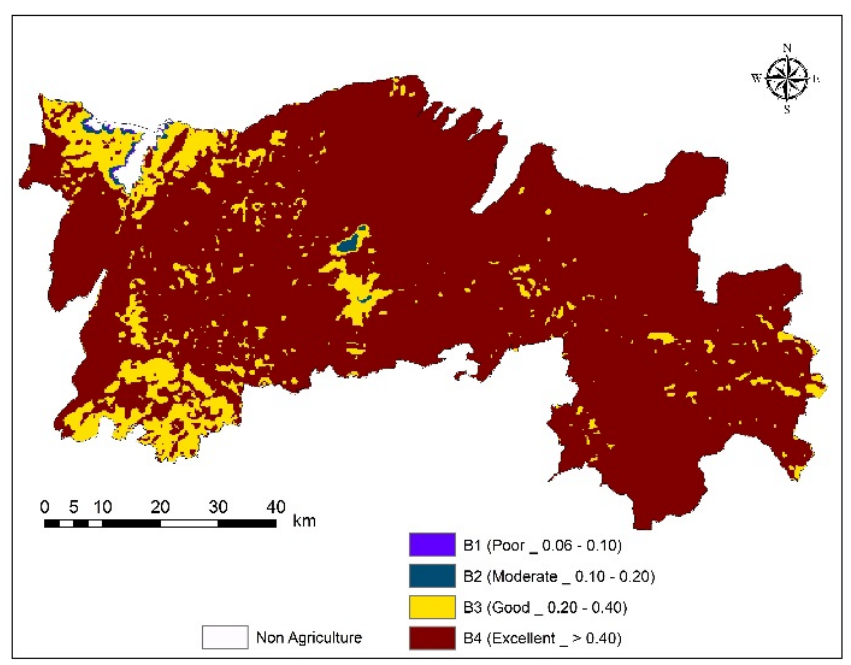

Figure 2. Biomass map of Salem

\section{CONCLUSION}

Sustainable agriculture is imperative to maintain the food security of a nation. This could be attained by efficient planning and utilization of available natural resources. The natural resources are to be categorized to obtain the area best suitable for crop production, so that they could be better utilized in agricultural planning. From the study it was concluded that under biomass more area was under excellent category followed by good category. This could pave way for better agricultural management and transfer of technology 


\section{REFERENCES}

Bala, S. K., B.U. Choudhury, Anil Sood, G. S. Bainsa and J. Mukherjee. 2005. Characterization of agro-ecological zones of Punjab state using remote sensing and GIS tools. In: ISPRS Archives XXXVIII-8/W3 Workshop Proceedings Impact of Climate Change on Agriculture, pp. 331-335.

Hansen, M., R.S. De Fries, J.R.G. Townshend, M. Carroll, C. Dimiceli, R.A. Sohlberg. 2003. Global percent tree cover at a spatial resolution of 500 meters: First Results of the MODIS Vegetation Continuous Fields Algorithm. Earth Interact., 7(10), pp.1-15.

Jin, S., and S.A. Sader. 2005. MODIS time-series imagery for forest disturbance and quantification of patch effects. Remote Sens. Environ. 99, pp. 462-470.

Rouse, J. W., R. H. Haas, J. A. Schell, D. W. Deering and J. C. Harlan. 1974. Monitoring the vernal advancements and retrogradation (Green wave effect) of natural vegetation, Report prepared for Goddard Space Flight Center, Greenbelt, Marryland, pp. 1-69.

Wilkie, D.S. and J.T. Finn.1996. Remote sensing imagery for natural resources monitoring. A guide for first time users. Methods and cases in conservation sciences series. Columbia University Press, New York. ISBN 0231079281. pp. 295. 